\title{
Avian Voices, Avian Silences: Learning By Listening to Birds
}

\author{
Nicole Sault ${ }^{1^{*}}$ \\ ${ }^{1}$ Sally Glean Center, Palo Alto, USA. \\ *nicole@sallyglean.org
}

Received October 3, 2020

OPEN Ә ACCESS

Accepted October 25, 2020

DOI 10.14237/ebl.11.2.2020.1730

Published December 4, 2020

Copyright $(\subset 2020$ by the author(s) licensee Society of Ethnobiology. This is an open-access article distributed under the terms of the Creative Commons Attribution-NonCommercial 4.0 International Public License (https://creativecommons.org/licenses/by-nc/4.0), which permits non-commercial use, distribution, and reproduction in any medium, provided the original author and source are credited.

Many societies honor birds as messengers and teachers with wisdom which offers resilience in addressing sudden changes or dealing with conflicts and crises. Now more than ever, as we perch on the edge of the global climate crisis that is exacerbated by continual warfare, an ethnobiological perspective offers us a way to better understand how to restore our relationship with the land and find healing.

This special issue on Avian Voices introduces research conducted in Peru, Costa Rica, Mexico, Indonesia, India, and the United States. The six papers present a variety of approaches that include analysis of historical documents on taxonomy and naming as well as contemporary research on metaphor and memory; the dynamic role of stories in transmitting cultural values; the responsibilities that reciprocal relationships with the environment entail; and women's roles in promoting community-based conservation.

The paper by Avila Najera, Tigar, ZavalaSanchez, Zetina-Cordoba, and Serna Lagunes addresses conservation concerns for birds in Mexico, where habitat loss and hunting threaten many species that are eaten, sold as pets, or used medicinally. Using calculations based on a Cultural Value Index (CVI), the authors compiled information on the status of birds in many regions of Mexico and coded how each species is used. While the common pigeon ranked highly as food, vultures and grackles were sought for healing. These authors demonstrate the utility of the CVI for documenting the reasons why birds are captured as well as highlighting threats to species survival. These data can inform sustainable conservation programs in Mexico, while addressing the needs of rural communities. The challenge is to apply this research to create effective communitybased conservation programs which can protect wildlife and habitats by working with local leaders.

Research which integrates conservation with community needs is also presented by Devi Barman, Sharma, Cockrem, Malakar, Kakati, and Melvin, growing out of their concern for the survival of the Adjutant Stork (Leptoptilos dubius) in Assam, India. The Adjutant Stork is the second rarest in the world and was on the edge of extinction due to habitat loss and poaching. However, in 2007, a conservation program was initiated by the researchers to work with three communities where the majority of the storks still survived. A women's group of conservation leaders was organized, together with village elders, youth, and visiting dignitaries. Their efforts were rewarded by a reduction in logging and poaching, and greater success of nests, as measured by increasing chick survival rates. Over 10,000 women joined in these efforts, and now their children have become leaders in protecting the storks. The success of this collaboration between researchers and community groups is demonstrated by the rise in the stork population from 400 birds at the beginning of the research to 950 in 2020.

Turning to Hawai' ${ }^{i}$, Gomes also addresses issues surrounding threats to birds and their habitat and connects this with cultural loss. He notes the extinction of over 74 of the 109 known endemic bird species in Hawai' $i$, while the surviving species have declined drastically and are rarely seen. When the birds disappear, so do their Hawaiian names. This means that as bird sounds are silenced, the chants that transmitted their names and associated stories also disappear. As part of the Native Hawaiian or kanaka 
maoli language and culture revitalization movement, Gomes examines historical records of bird classification and nomenclature dating from the $1840 \mathrm{~s}$ to the 1860s. He analyzes the works of Hawaiian avian experts David Malo and Kepelino Teauotalani, who documented kanaka maoli bird taxonomies. Gomes' analysis also includes the 1903 work of the English naturalist, Robert Perkins. This contemporary research shines a light on how bird taxonomies were structured and the cultural understandings underlying the names given to birds. In Hawaiian avian taxonomies, bird names express specific cultural knowledge in relation to calls, plumage, beak form, eating habits, eyesight, and holy persons who are affiliated with certain species. Awareness of the cultural context for bird names enables us to understand unusual meanings and linkages, as when forest-dwelling birds are called fish-eaters (Gomes 2020:35). Highlighting the work of these early scholars encourages the revitalization of the kanaka maoli heritage to inform both current and future decisions and actions.

Pierotti examines the interweaving of ecology, history, and language in his analysis of metaphor in Native American oral traditions. He shows how ethnography and historical knowledge can elucidate the deeper meanings that metaphors encode.

His analysis focuses on stories featuring Corvidae species-Ravens, Crows, Jays, and Magpies_as a means for exploring the empirical basis of oral traditions. Drawing on examples from the Apache, Koyukuk, Cheyenne, Cree, and Anishinaabe in the U.S. and Canada, he describes the special roles of Corvids as agents of change, tricksters, and teachers who cooperate with humans and demonstrate proper relationships with other creatures and the land. In these societies, people wear feathers as a sign of solidarity with their two-legged, winged, relatives (Pierotti 2020:47). Pierotti (2020:45) also incorporates wolves in this discussion, based on the close connection between wolves and birds; for example, he describes ravens as "wolf-birds" because of their cooperative hunting relationships. Just as the Hawaiian chants that Gomes describes are important for memory and passing on cultural knowledge, so the stories Pierotti presents serve to dramatize values and fix these in the socio-cultural memory of each group. He notes that such information is crucial for cultural continuity and even physical survival as birds alert humans to food sources and guide them to prey.
Metaphor and empirical experience are also the focus of Forth's paper on the Nage of Flores Island in eastern Indonesia. Birds communicate through their own voices and through metaphors-providing ways for humans to talk about both the behavior of birds and also people who share the qualities of particular birds, such as the Orange-footed scrubfowl (Megapodius reinwardt). Just as Pierotti includes wolves in his discussion of Corvids, Forth also considers the relationship between birds and other animals, like sea turtles. This relationship is expressed in metaphors about reproduction and morality, in reference to the scrubfowl's negligent style of maternal parenting. Forth observes how shared metaphors associated with birds and turtles illustrate ways in which creatures lacking any connection in folk zoological taxonomy can be linked symbolically through their behaviors. These Nage beliefs reflect morphological and behavioral similarities in the ways that different creatures are perceived, such that spatial proximity is believed to connect their physical shape and identity. Transformation beliefs about birds and turtles explain how one can change into another, with discontinuities in their relationships resulting in morphological changes. As in the Gomes paper, Forth shows how seemingly unusual linkages between scrubfowl and sea turtles are derived from metaphorical meanings related to their behavior.

My own contribution to this volume considers the role of stories in Mexico, Costa Rica, and Peru, with examples that illustrate how personal experiences with birds connect people to their cultural traditions and practices which provide resilience. Three stories from Zapotec, Bribri, and Quechua-speaking people portray interrelationships between people and birds through an ongoing dialogue. While people attend to avian voices, they in turn speak to the birds; through these interactions a more intimate connection develops with their surroundings. Avian voices are recognized as meaningful because birds are seen as social actors with intentions, desires, needs, and responsibilities. Birds are beings with spiritual significance as either messengers of the gods or their personification. Rather than focusing on shared myths or other stories that are widely known, these three stories portray particular encounters with specific birds. Such encounters are interpreted according to each person's experiences and woven together with the meaning of the bird's message for their families, as understood in the context of both traditional values and current situations. The dynamic nature of these stories of bird 
wisdom and warning provides a resource that people can draw upon in times of dramatic change, such as the drought and flooding related to the global climate crisis. By attending to avian voices and behaviors, people feel they can be guided through situations of uncertainty or danger, which gives these stories greater significance and urgency.

Several of these contributions (Avila Najera, Tigar, Zavala-Sanchez, Zetina-Cordoba, and Serna Lagunes; Devi Barman, Sharma, Cockrem, Malakar, Kakati, and Melvin; Gomes; Sault) raise the issue of avian silence and what this means. The silence of birds may be due to habitat loss, extinction, or climate change, which has altered weather patterns that affect migration, feeding, and breeding. Additionally, in many cultures the silence of birds is interpreted as a warning of disapprobation or danger. Such portents can be seen as a reflection of how the land is faring and a measure of a people's relationship to place. Silence can be ominous-representing the judgement of the ancestors or the deities who can withhold blessing or send illness and punishment.

Interspecies communication between people and birds is not unidirectional from birds to people, as people may not only listen to birds but also talk with them. For the Nahua of Alto Balsas, Mexico, relationships between people and birds are connected to food and empathy in a complex network of interactions framed by working, feeding, and loving (Raby 2013). As Raby explains, they consider animals not only "good for thinking" but "good for living together" [translation mine]. Yet, in many places people are losing the ability to hear birds and understand their messages or communicate with them. People are forgetting how to listen and attend to birds. As the Tzotzil Maya poet, Manuel Bolom, observes: "The birds dialogue with the community, tell dreams, but the ones who listen are those with understanding" (cited in Vásquez-Dávila 2014, translation mine).

The loss of listening and understanding has in turn influenced the loss of stories, songs, and chants. In the old Aymara song, "Kuntur Mamani," Elvira Espejo Ayca of Bolivia sings in Spanish "Cuando se pone la paja en el techo...te protegerá como las alas del condor" (When the house roof is thatched...it will protect you like the wings of the condor) (Espejo
Ayca 2011) (translation mine). Espejo Ayca told me that when the old Aymara songs she recorded were played by a local radio station, the old people wept, for they had not heard these songs in such a long time.

When the stories, songs, and chants are no longer passed down, the knowledge and wisdom encoded in those stories disappears (Gomes, this volume). For many peoples, these stories are crucial for cultural and even physical survival (Pierotti, this volume; Raj 2019). The present collection of papers on avian voices and silences is offered as a contribution to recovering this knowledge and as a guide in the ongoing work to restore and protect birds, their habitats, and the peoples who are their companions and relatives.

\section{Acknowledgments}

I wish to thank Ethnobiology Letters editor Liz Olson for her patient perseverance in bringing this volume to fruition.

\section{Notes}

This special section on ethno-ornithology grew out of a session I organized for the 2019 Society of Ethnobiology meeting held in Vancouver, British Columbia, Canada, on May 10, entitled "Avian Voices in Song, Story, Wisdom and Warning."

\section{References Cited}

Espejo Ayca, E. 2011. Cantos a las Casas: Utach Kirki, Jiyawa Música [Audio]. Available at: http:// opacespacio.fundacionpatino.org/cgi-bin/koha/ opac-detail.pl?biblionumber $=21621$. Accessed on October 13, 2020.

Gomes, N. J. 2020. Reclaiming Native Hawaiian Knowledge Represented in Bird Taxonomies. Ethnobiology Letters 11:30-43. DOI:10.14237/ ebl.11.2.2020.1640.

Pierotti, R. 2020. Learning about Extraordinary Beings: Native Stories and Real Birds. Ethnobiology Letters 11:44-51. DOI:10.14237/ebl.11.2. 2020.1682.

Raby, D. 2013. Comidas del Zopilote: Ofrenda, Limpieza y Empatía en un Ritual Agrícola (Alto Balsas Nahua, México). Amérique Latine, Histoire e Mémoire 25. DOI:10.4000/alhim.4496. 
Raj, A. 2019. In Marshall Islands, Radiation Threatens Tradition of Handing Down Stories by Song. Los Angeles Times. Available at: https:// www.latimes.com/projects/marshall-islandsradiation-effects-cancer/. Published November 10, 2019.
Vásquez-Dávila, M. A., ed. 2014. Aves, Personas y Cultura: Estudios de Etno-mitología 1. Carteles Editores, Oaxaca, México. 